\title{
Size- and charge selectivity of glomerular filtration in Type 1 (insulin-dependent) diabetic patients with and without albuminuria
}

\author{
T. Deckert ${ }^{1}$, A. Kofoed-Enevoldsen ${ }^{1}$, P. Vidal ${ }^{1}$, K. Norgaard ${ }^{1}$, H. B. Andreasen ${ }^{2}$, B. Feldt-Rasmussen ${ }^{1}$ \\ ${ }^{1}$ Steno Diabetes Center, Gentofte, Denmark \\ ${ }^{2}$ Pharmacosmos A/S, Viby, Denmark
}

\begin{abstract}
Summary. Albuminuria is the first clinical event in the development of diabetic nephropathy. We assessed glomerular charge- and size selectivity in 51 patients with Type 1 (insulin-dependent) diabetes mellitus of juvenile onset and 11 healthy individuals. Patients were allocated to five groups. The urinary albumin excretion rate was normal in group D1; $30-100 \mathrm{mg} / 24 \mathbf{h}$ in group D2; $101-300 \mathrm{mg} / 24 \mathbf{h}$ in group D3 and greater than $300 \mathrm{mg} / 24 \mathrm{~h}$ in groups D4 and D5. Group D5 had elevated serum creatinine (above $110 \mu \mathrm{mol} / \mathrm{l}$ ). Glomerular filtration rate and renal plasma flow were determined by constant infusion techniques and tubular protein reabsorption by excretion of $\beta 2$-microglobulin. Charge selectivity was estimated from the $\operatorname{IgG} / \operatorname{IgG} 4$ selectivity index. Size selectivity was measured by dextran clearance. Dextran was measured by refractive index detection after fractionation ( $2 \AA$ fractions in the range $26-64 \AA$ ) by size exclusion
\end{abstract}

chromatography. IgG/IgG4 selectivity index was significantly decreased in patients with albuminuria $(p<0.001)$. The drop in $\mathrm{IgG} / \mathrm{IgG} 4$ selectivity index was found in patients with minimal albuminuria (D2) and was not accompanied by any changes in tubular function or glomerular haemodynamics. Size selectivity was significantly altered only in patients with the most advanced nephropathy (D5) as reflected by an increase in the clearance of $62 \AA$ dextran $(p<0.04)$. We conclude that loss of glomerular charge selectivity precedes or accompanies the formation of new glomerular macromolecular pathways in the development of diabetic nephropathy.

Key words: Diabetes mellitus, dextran clearance, $\operatorname{IgG} 4$, $\operatorname{IgG}$, IgG/IgG4 selectivity index, diabetic nephropathy, tubular function.
Albuminuria is the first clinical sign in patients with Type 1 (insulin-dependent) diabetes mellitus who are developing clinical nephropathy [1]. Albuminuria is of glomerular origin [2], however, the cause of increased glomerular albumin flux is unknown. In addition to increased intra-glomerular pressure [3], loss of glomerular charge selectivity [4] and altered glomerular size selectivity [5] seem also to be present in Type 1 diabetic patients with advanced clinical nephropathy. We have previously reported evidence of reduced charge selectivity at the onset of microalbuminuria [4]. However, in that study charge selectivity could be measured in less than one-half of our patients and the differences in the charge selectivity index (IgG/IgG4 selectivity index) did not reach statistical significance. It is also not clear whether impaired glomerular size selectivity is present in diabetic patients early in the course of clinical nephropathy, when the glomerular filtration rate (GFR) is normal or only slightly decreased. Having improved the IgG/IgG4 measurements and established fractionated dextran clearance, we studied glomerular size- and charge-selectivity in patients with Type 1 diabetes who had different levels of albuminuria ranging from normal urinary albumin excretion rate (UAE) to microalbuminuria and macroalbuminuria with elevated serum creatinine.

\section{Subjects and methods}

\section{Subjects}

The protocol was approved by the Regional Scientific Ethical Committee and the participants gave informed consent. The study groups comprised 55 Type 1 diabetic patients (groups D1-D5) and 12 healthy control subjects (group C). Persistently elevated UAE of more than $30 \mathrm{mg} / 24 \mathrm{~h}$ for more than 1 year had been noted for $42 \mathrm{pa}-$ tients. Four subjects were excluded due to voiding problems during the clearance studies (one patient from group C, D1, D2 and D4, respectively) and one patient from group D1 was excluded due to technical failure of the infusion pump.

All patients were Caucasian and had been treated with insulin from the onset of diabetes before the age of 31 years. On the basis of serum creatinine and the median of the last three determinations of UAE within 12 months, the patients were allocated to one of five different groups: 
D1: $\mathrm{UAE}<30 \mathrm{mg} / 24 \mathrm{~h}$

D2: UAE $30-100 \mathrm{mg} / 24 \mathrm{~h}$

D3: UAE $101-300 \mathrm{mg} / 24 \mathrm{~h}$

D4: UAE $>300 \mathrm{mg} / 24 \mathrm{~h}$

D5: UAE $>300 \mathrm{mg} / 24 \mathrm{~h}$

creatinine $<110 \mu \mathrm{mol} / 1$

creatinine $<110 \mu \mathrm{mol} / 1$

creatinine $<110 \mu \mathrm{mol} / 1$

creatinine $<110 \mu \mathrm{mol} / 1$

creatinine $\geq 110 \mu \mathrm{mol} / \mathrm{l}$

None of the subjects studied had known non-diabetic renal disease, signs of urinary tract infection or cardiac diseases. Antihypertensive therapy were given in 20 patients (thiazides, furosemide (18 patients), metropolol (1 patient), and $\mathrm{Ca}^{2+}$ antagonists ( 6 patients)) but not on the day of study. Further clinical characteristics are listed in Table 1.

\section{Experimental protocol}

The studies were started in the morning, following an overnight fast. All subjects were in the supine position except when voiding. Starting $1 \mathrm{~h}$ before the study, $200 \mathrm{ml}$ of tap water was given orally every $20 \mathrm{~min}$. Blood glucose was kept between 3.5 and $16 \mathrm{mmol} / 1$, if necessary by i.v. injection of small amounts of insulin. After resting for $1 \mathrm{~h}$, glomerular filtration rate (GFR) and renal plasma flow (RPF) measurements were initiated and dextran infusion was started $50 \mathrm{~min}$ thereafter. Finally, following a 70-min equilibration period, 3-5 timed ( $20 \mathrm{~min}$ ) urine collections were made. Venous blood samples were taken $7 \mathrm{~min}$ after each urine collection.

\section{GFR and RPF}

Constant infusion of iothalamat $(1.1 \mathrm{mg} / \mathrm{min}$ Conray, $67 \%$; AstraMeditec, Albertslund, Denmark) and aminohippurate sodium (PAH) $(10 \mathrm{mg} / \mathrm{min}, 20 \%$; Merck, Sharp \& Dohme, Herlev, Denmark) was started after priming $(5 \mathrm{mg} / \mathrm{kg}$ of both iothalamat and $\mathrm{PAH}$ ). To prevent the formation of PAH glucose adducts in urine, $2 \mathrm{ml}$ urine samples were alkalinized with $25 \mu \mathrm{l}$ of $2 \mathrm{~mol} / 1$ sodium hydroxide [6]. An HPLC system with an ultraviolet detector was used to assay iothalamat and PAH at $236 \mathrm{~nm}$ (UVIS 200 Linear; Mikrolab AS, Aarhus, Denmark). Ultra-filtrates of plasma and diluted urine were injected onto a reverse phase column (C-18 $5 \mu$ Ultrasphere; Beckman, San Ramon, Calif., USA). The mobile phase was $4 \%$ acetonitril, $10 \mathrm{mmol} / 1$ trimethylamine and $10 \mathrm{mmol} / 1$ phosphoric acid $\mathrm{pH} 3.0$ at a flow rate of $0.9 \mathrm{ml} / \mathrm{min}$. Iothalamat and PAH concentrations were determined from the peak area of each solute corresponding to column retention times of 18 and $11 \mathrm{~min}$, respectively. The coefficient of variation on the same day was 5 and $6 \%$, from day to day 8.8 and $9.1 \%$, respectively. The coefficient of variation between the individual clearance periods was $10.9 \%$.

\section{Dextran clearance}

Dextran infusion (10\% dextran 40, Rheomacrodex; Pharmacia, Uppsala, Sweden) at a rate of $130 \mathrm{mg} \cdot \mathrm{kg}^{-1} \cdot 10 \mathrm{~min}^{-1}$ was started after a priming injection of low molecular dextran $(3 \mathrm{~g}$ in $20 \mathrm{ml}$, mol. wt.

Table 1. Clinical characteristics of control (C) and patient groups (D1-D5)

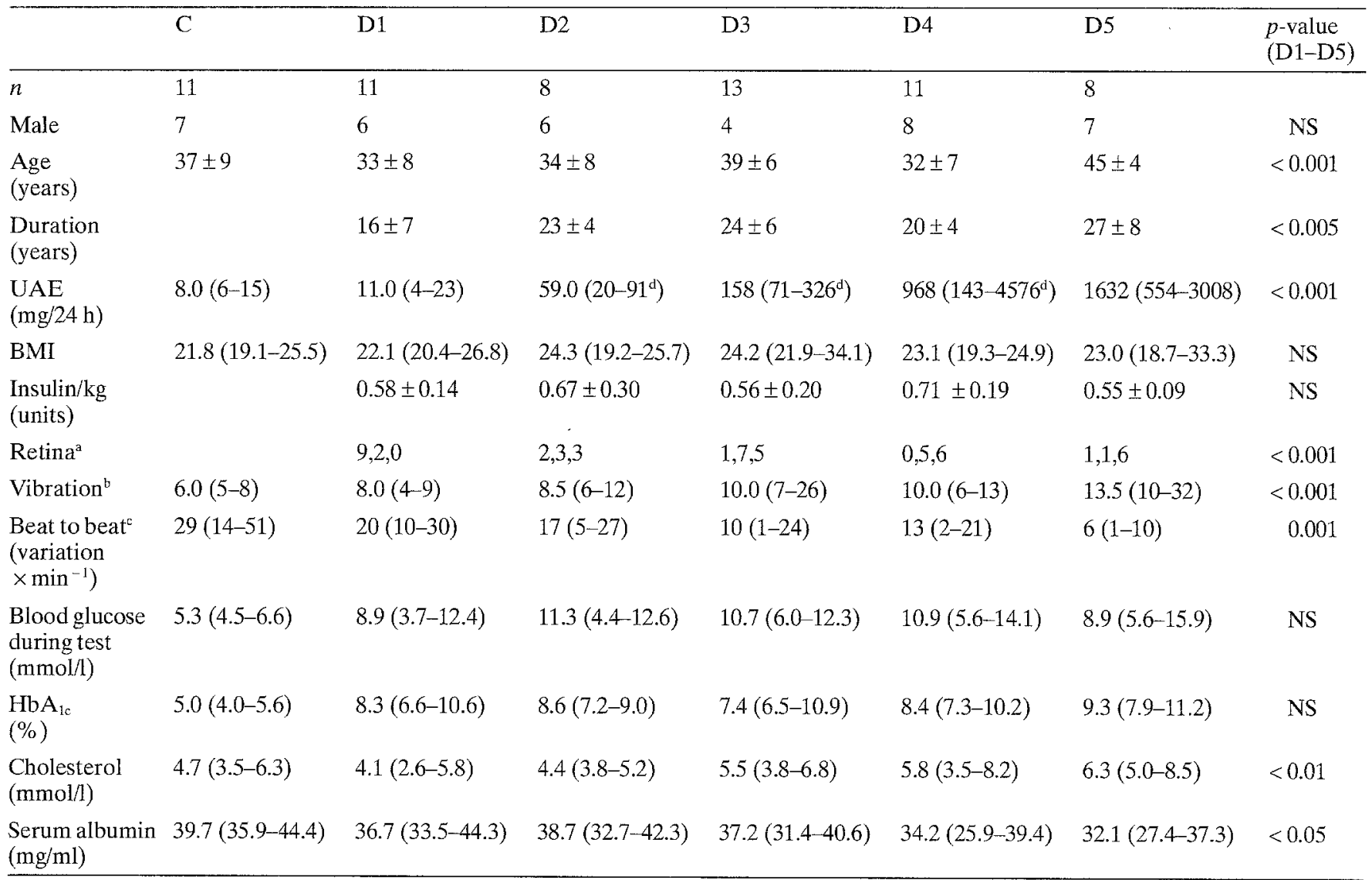

Type 1 diabetic patients with normal urinary albumin excretion rate (UAE) (D1), UAE 30-100 mg/24 h (D2), UAE 101-300 mg/24 h (D3), UAE $>300 \mathrm{mg} / 24 \mathrm{~h}$ and serum creatinine $<110 \mu \mathrm{mol} / \mathrm{l}$ (D4) and UAE $>300 \mathrm{mg} / 24 \mathrm{~h}$ and creatinine $\geq 110 \mu \mathrm{mol} / \mathrm{l}$ (D5).

Results are presented as mean $\pm \mathrm{SD}$ or as median (range)

\footnotetext{
${ }^{a}$ No changes, background retinopathy, proliferative retinopathy and/or blindness;

${ }^{b}$ normal $\leq 15$;

${ }^{2}$ normal $>10$;

din a few patients actual UAE was decreased due to antihypertensive treatment
} 
Table 2. Renal function during forced diuresis in healthy control subjects (C) and Type 1 diabetic patients without (D1) and with albuminuria (D2-D5) (for definition of groups see Subjects and methods)

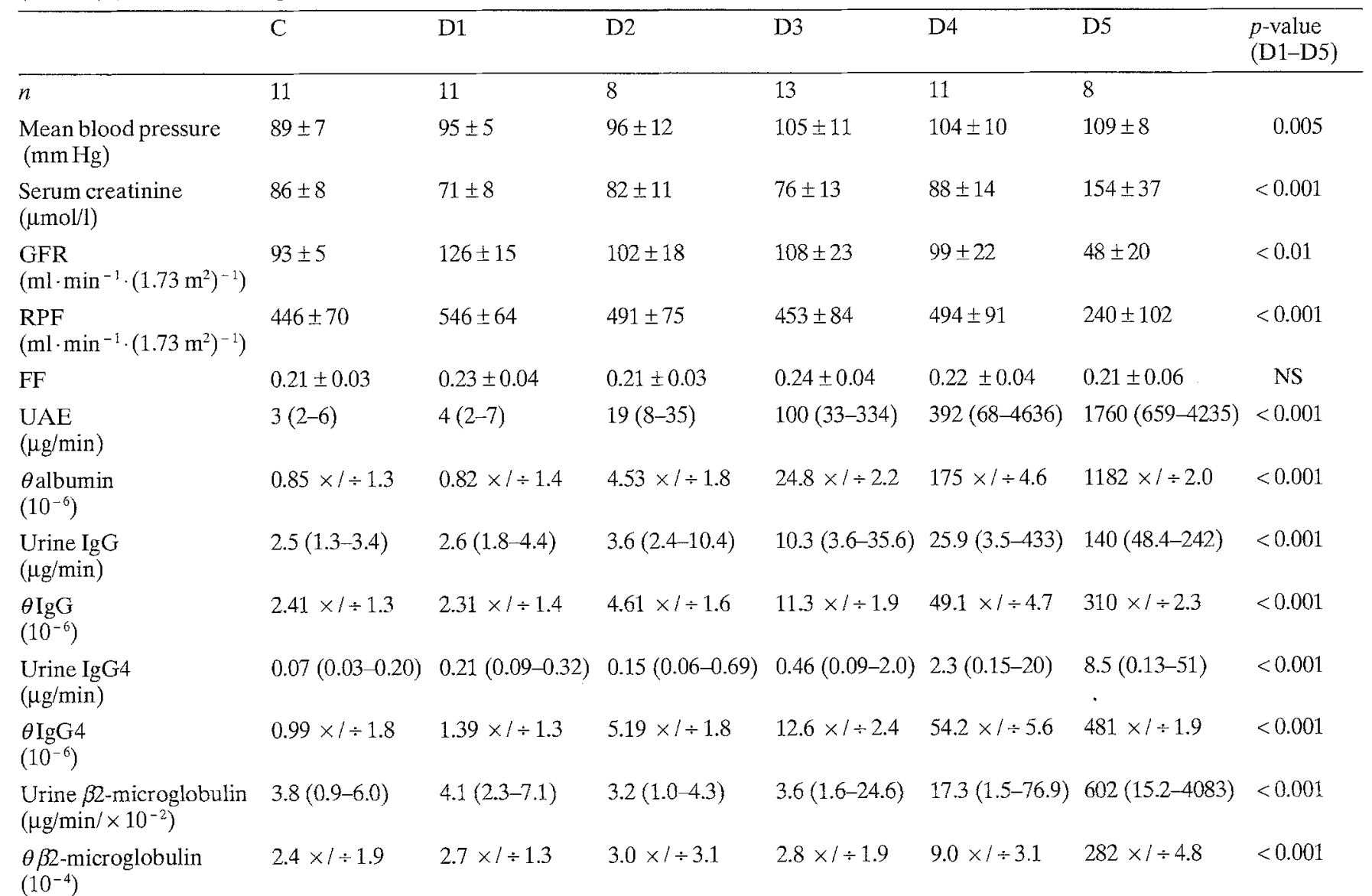

Results are presented as mean $\pm \mathrm{SD}$, mean $x / \div$ tolerance factor, or as median (range). GFR, Glomerular filtration rate; RPF, renal plasma flow; FF, filtration fraction (GFR/RPF); $\theta$, fractional clearance

$1 \mathrm{kDa}$ (Promiten; Pharmacia)) in order to avoid allergic reactions [7]. Dextran in plasma was determined after hydrolysis of proteins with $\mathrm{NaOH}$ and removal of peptides by $\mathrm{ZnSO}_{4}$ precipitation. After centrifugation the supernatant was ion-exchanged using Duolite resins A113 and C20 (Duolite International, Vitry-sur-Seine, France) and filtered through a $0.45 \mu \mathrm{m}$ disposable Nalgene filter before lyophilization. Urine underwent the ion-exchange procedure without hydrolysis of proteins. The recovery of dextran was greater than $95 \%$ and no changes in the distribution pattern were observed. Dextran size fractioning in $2 \AA$ intervals were performed by size exclusion chromatography (GPC) using a Waters chromatograph with four columns in series (TSK PW 3000, 4000, 5000 and 6000; Toyosoda, Tokyo, Japan) under temperature control at $30^{\circ} \mathrm{C}$ using refractive index detection. Chromatograms were analysed using Pharmacosmos-developed software (Viby, Denmark). Calibration was performed using 10 different standards of narrow ranges of molecular size (1000-400000 peak mol · wt.) (Pharmacosmos Dextran Stan dards; Pharmacosmos). On each day dextran 25, dextran 50 and Rheomacrodex were also measured. The day to day coefficient of variation in the calculated weight average molecular weight $\left(\mathbf{M}_{W}\right)$ and number average molecular weight $\left(\mathrm{M}_{\mathrm{n}}\right)$ of these three dextran preparations was $1.0-2.1 \%$.

\section{Albumin, IgG, IgG4 and $\beta 2$-microglobulin clearances}

Albumin, IgG, IgG4 and $\beta 2$-microglobulin were measured in serum and in the timed urine samples with enzyme linked immunosorbent assay (ELISA) as previously described [8-11]. Intra- and inter-assay coefficients of variation were below $5 \%$ and $10 \%$ respectively in all assays. The IgG4 assay was not sensitive enough (detection limit $2 \mu \mathrm{g} / \mathrm{l}$ ) to measure the concentration of $\operatorname{IgG} 4$ in urine during water diuresis in all patients, thus total IgG and IgG4 concentrations were also measured in the urine and blood samples taken before water diuresis was established.

\section{Other measurements}

Haemoglobin $\mathrm{A}_{1 \mathrm{c}}\left(\mathrm{HbA}_{\mathrm{lc}}\right)$ was measured by HPLC (Biorad, Diamat, Richmond, Calif., USA), normal range 4.3-6.2\%. Blood pressure was measured several times before and during the study using a standard sphygmomanometer. Diastolic blood pressure was recorded when the Korotkoff sounds disappeared (phase V). Vibration perception threshold was measured with a hand-held Biothesiometer (Biomedical Instrument, Newbury, Ohio, USA) over the first right toe [12] and expressed as the mean of three measurements. Autonomic neuropathy was assessed by beat-to-beat variation [13]. Other measurements included serum creatinine, cholesterol, haematocrit, blood glucose, $\mathrm{Na}^{+}$and $\mathrm{K}^{+}$.

\section{Calculations}

GFR and RPF were calculated as the mean of the values from the timed urine collections. Fractional protein or dextran clearances $(\theta)$ were calculated as 
Table 3. Serum (S) and urine (U) IgG and IgG4 concentrations (median (range)) before water diuresis in healthy control subjects (C) and Type 1 diabetic patients without (D1) and with albuminuria (D2-D5), (for definition of groups see subjects and methods)

\begin{tabular}{|c|c|c|c|c|c|c|c|}
\hline & $\mathrm{C}$ & D1 & D2 & D3 & D4 & D5 & $p$-value (D1-D5) \\
\hline $\begin{array}{l}\text { S-IgG } \\
(\mathrm{g} / \mathrm{l})\end{array}$ & $\begin{array}{l}9.41 \\
(6.5-10.9)\end{array}$ & $\begin{array}{l}8.20 \\
(5.3-11.2)\end{array}$ & $\begin{array}{l}7.06 \\
(6.2-12.9)\end{array}$ & $\begin{array}{l}9.11 \\
(6.8-12.0)\end{array}$ & $\begin{array}{l}6.49 \\
(4.5-9.3)\end{array}$ & $\begin{array}{l}7.98 \\
(5.5-10.5)\end{array}$ & NS \\
\hline $\begin{array}{l}\text { U-IgG } \\
(\mathrm{mg} / \mathrm{l})\end{array}$ & $\begin{array}{l}0.97 \\
(0.46-3.70)\end{array}$ & $\begin{array}{l}1.86 \\
(0.33-12.2)\end{array}$ & $\begin{array}{l}150 \\
(0.34-3.24)\end{array}$ & $\begin{array}{l}7.04 \\
(1.21-16.7)\end{array}$ & $\begin{array}{l}20.72 \\
(2.45-97.0)\end{array}$ & $\begin{array}{l}41.65 \\
(13.2-80.0)\end{array}$ & $<0.001$ \\
\hline
\end{tabular}

urinary protein (dextran) excretion

serum protein (dextran) concentration $\times$ GFR

All clearances were corrected to a body surface area of $1.73 \mathrm{~m}^{2}$. The $\mathrm{IgG} / \mathrm{IgG} 4$ selectivity index (SI) was calculated as clearance of IgG/clearance of IgG4. This ratio of the clearance of two plasma proteins of identical size but different charge i. e. total $\operatorname{IgG}$ (Stoke radius $55 \AA$, pI 7.3 (range 6-10)) and IgG4 (Stoke radius $55 \AA$, pI 5.8) was taken as an index of glomerular charge selectivity.

\section{Statistical analysis}

Standard unpaired parametric statistics, two-tailed significance level $p$ less than 0.05 , were applied. The protein clearances followed normal distribution when logarithmically transformed. One way analysis of variance with Duncans multiple range test was used to detect group differences.

\section{Results}

The clinical data are given in Table 1. Patients in group D5 were older, had a longer duration of disease and a higher $\mathrm{HbA}_{1 \mathrm{c}}$. Total cholesterol was higher, serum albumin lower and retinopathy and neuropathy more severe in patients with clinical nephropathy. One patient in group D5 had no signs of retinopathy, but renal biopsy demonstrated severe nodular glomerulosclerosis without signs of other renal disease. Patient mean blood glucose concentration was $9.3 \mathrm{mmol} / \mathrm{l}$ during the study. Blood pressure increased concomitantly with UAE in diabetic patients with albuminuria (Table 2). Patients in group D1 had glomerular hyperfiltration and hyperperfusion. Also the filtration fraction tended to be elevated, although not significantly, compared to D2 ( $p=0.13$ for D1 vs D2).

The urinary excretion of $\beta 2$ microglobulin, a marker of tubular function, was normal in patients with UAE less than $300 \mathrm{mg} / 24 \mathrm{~h}$ but increased in group D5 (Table 2).

Mean fractional clearance of IgG4 was $50 \%$ lower than total IgG clearance in control subjects and D1, whereas the clearances were similar in group D2-D5 (Table 2). Urinary IgG4 could not be measured during water diuresis in 15 subjects, mainly from groups C and D1. Thus urine sampled before water diuresis was preferable for the further calculation of the $\mathrm{IgG} / \mathrm{IgG} 4$ selectivity index (SI) (Table 3). This reduced the number of excluded subjects to six (two in C, three in D1 and one in D4). A good correlation was found between SI's measured during water diuresis and the SI's measured before water diuresis was induced $(r=0.72, p=0.001, n=47)$. In the albuminuric groups SI was significantly reduced $(p=0.001)$, indicating loss of glomerular charge selectivity in these patients (Fig. 1). The reduction in SI was present even in patients with microalbuminuria in the lowest range (30$100 \mathrm{mg} / 24 \mathrm{~h})(p=0.01$ for D1 vs D2). No further decrease in SI was seen in patients with more advanced albuminuria. Treatment with antihypertensive drugs had no effect on SI which was also unrelated to diabetes duration, GFR, $\mathrm{HbA}_{1 \mathrm{c}}$, age and sex (data not shown). Total IgG clearance was significantly elevated in groups D3-D5 compared to $\mathrm{C}, \mathrm{D} 1$ and D2, whereas no significant differences were found between C, D1 and D2 (Table 2).

Clearance of dextrans sized $28-60 \AA$ could be calculated in all but six subjects (two in D1, two in D2, one in D3 and one in D5) in which the dextran assay was not sensitive enough for urinary dextran $60 \AA$. At $62 \AA$ the corresponding number of patients excluded from the calculation was 23 (two in C, five in D1, three in D2, five in D3, four in D4, four in D5) and at $64 \AA$, the number was 32 (five in $\mathrm{C}$, seven in D1, five in D2, six in D3, five in D4, four in D5). Fractional dextran clearances are shown in Fig-

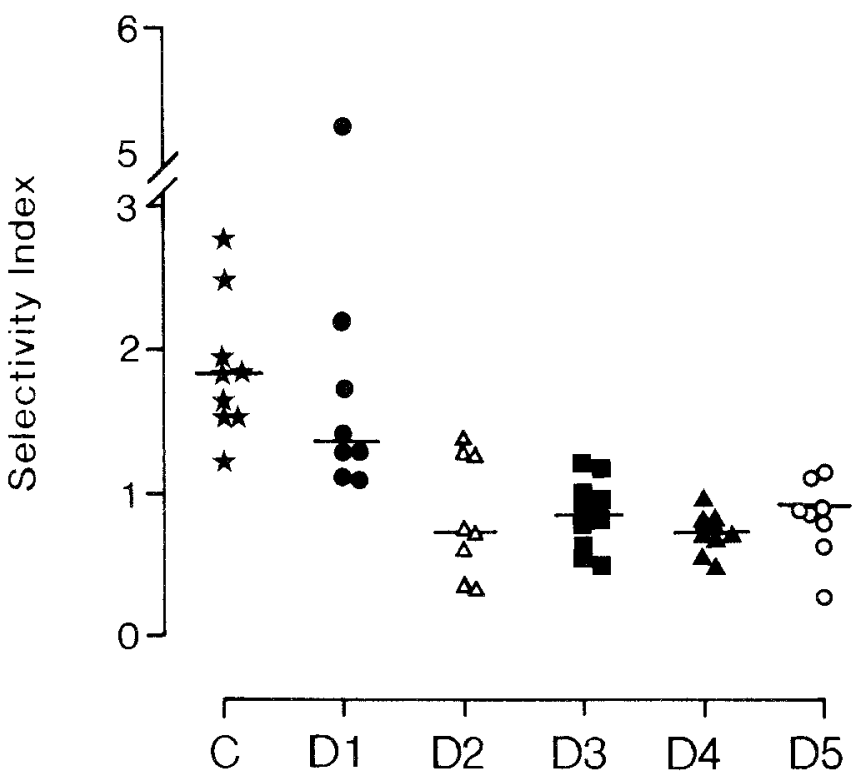

Fig. 1. Selectivity index (SI) - defined as clearance of $\mathrm{IgG} /$ clearance of $\mathrm{IgG} 4$ before water diuresis - in healthy control subjects (C), Type 1 diabetic patients with normal urinary albumin excretion (UAE) (D1) and persistently elevated UAE (D2-D5). SI was significantly decreased in D2-D5 compared to C and D1 $(p=0.001)$ 


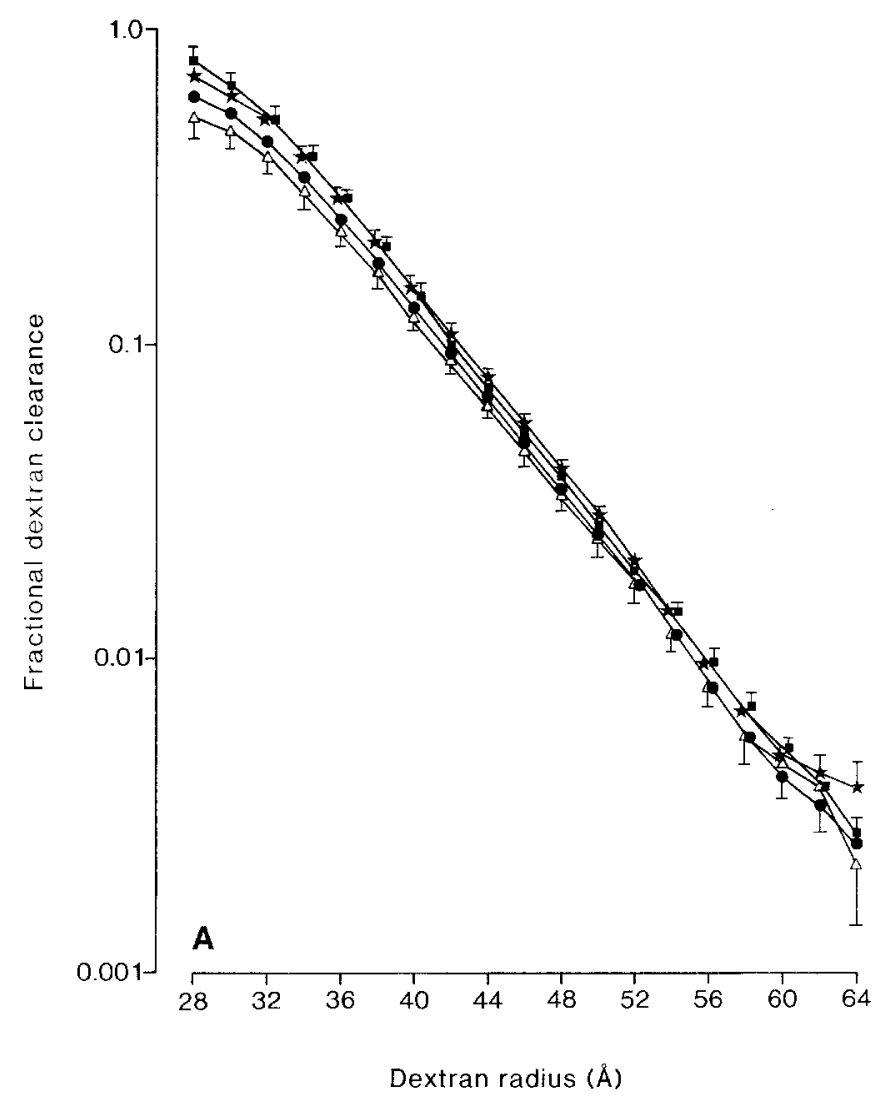

Fig. 2A, B. Fractional clearance (mean \pm SEM) of dextrans of different sizes. A Healthy control subjects $(C, n=11, \star)$, Type 1 diabetic patients with: normal urinary albumin excretion (UAE) $<30 \mathrm{mg} / 24 \mathrm{~h}(\mathrm{D} 1, n=11, \bullet)$ UAE $30-100 \mathrm{mg} / 24 \mathrm{~h}(\mathrm{D} 2, n=8, \triangle)$, and UAE $101-300 \mathrm{mg} / 24 \mathrm{~h}(\mathrm{D} 3, n=13$, $\mathbf{\square})$. B Type 1 diabetic pa-

ure 3. The fractional dextran clearance at $62 \AA$ was significantly elevated in group D5 when compared to group D1-D4 $(p<0.04)$. Otherwise no significant differences in dextran clearances between the groups were found (Fig. 2). In the albuminuric groups (D2-D5), both GFR and fractional IgG clearance correlated significantly with fractional dextran clearances in the range 58-62 $\AA$, the strongest correlations being with $62 \AA$ clearance $(r=$ $-0.70, p=0.0002$ and $r=0.56, p=0.004, n=24$, for GFR and $\operatorname{In}(\theta \mathrm{IgG})$ respectively. The correlations remained significant although weakened when normoalbuminuric patients (D1) were included. No differences were found in slope of the dextran clearance curves or in the clearance of dextrans less than $40 \AA$ in the albuminuric groups compared to $\mathrm{C}$ or D1. Dextran clearances were however generally lower in normoalbuminuric patients (D1) compared to healthy control subjects (Fig.2A). Antihypertensive treatment had no effect on fractional dextran clearance.

Groups D2-D5 were heterogeneous regarding GFR, and since GFR potentially influenced the fractional clearance of large dextrans, the patients in group D2-D5 were allocated to two groups according to whether their GFR was above $(n=21)$ or below $(n=19) 90 \mathrm{ml} \cdot \mathrm{min}^{-1}$. $\left(1.73 \mathrm{~m}^{2}\right)^{-1}$ (Table 4). Comparing these two albuminuric groups revealed a tendency towards an increase in the fractional clearance of dextrans above $56 \AA$ in the group

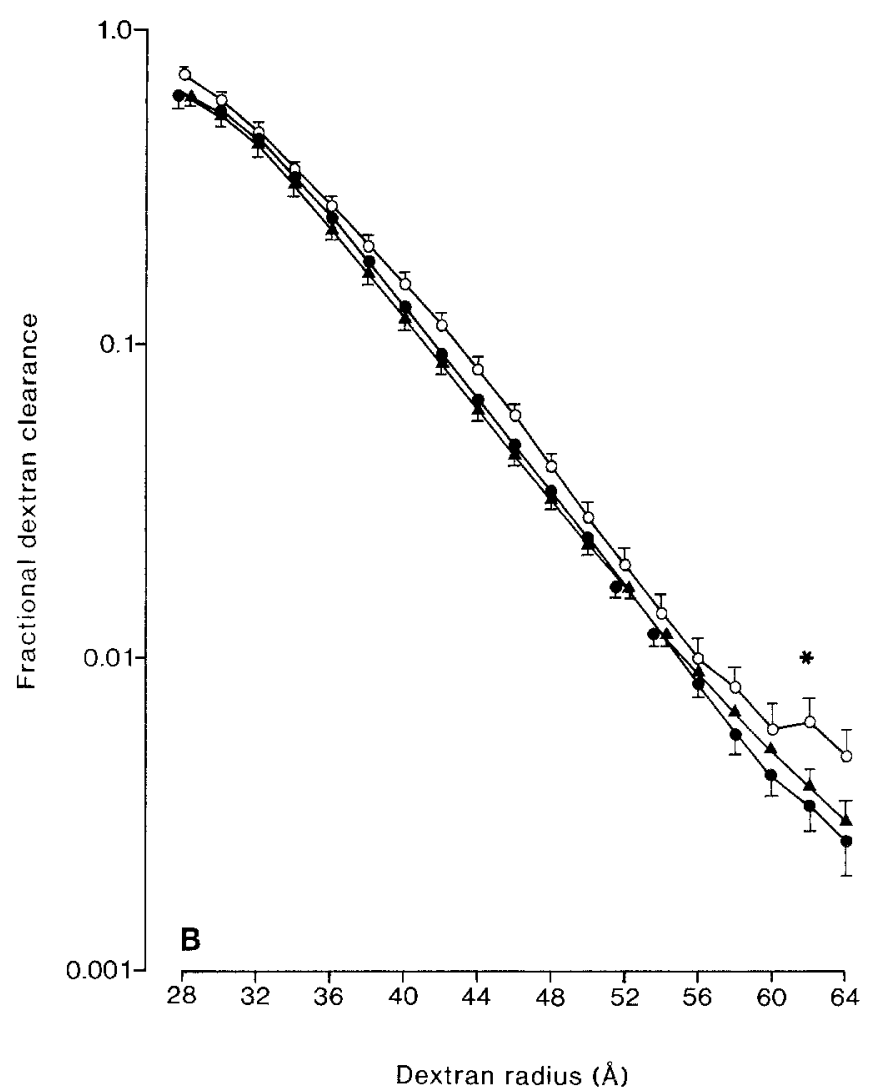

tients with UAE $>300 \mathrm{mg} / 24 \mathrm{~h}$ and serum creatinine $<110 \mu \mathrm{mol} / \mathrm{l}$ (D4, $n=11, \boldsymbol{\Delta}$ ), UAE $>300 \mathrm{mg} / 24 \mathrm{~h}$ and serum creatinine $>110 \mu \mathrm{mol} / 1(\mathrm{D} 5, n=8,0)$ compared to Type 1 diabetic patients with normal UAE. * $p<0.04$

with reduced GFR as seen in Figure 3. The clearances of $58 \AA$ and $60 \AA$ dextran were significantly elevated in the group with reduced GFR compared to normoalbuminuric patients (D1) $(p<0.05)$ and at $62 \AA$ became significantly different also from albuminuric patients with normal GFR. A significant correlation was found between GFR and fractional $62 \AA$ dextran clearance in the low-GFR group ( $r=-0.66, p=0.02, n=12)$, but not with other dextran clearances or with fractional IgG clearance. No significant correlations between these parameters were present in the albuminuric group with normal GFR.

Table 4. Characteristics of renal function in Type 1 diabetic patients with normal (D1) or elevated urinary albumin excretion (UAE) $\left(D_{2-5} A\right.$ and $B$ ) regrouped according to level of glomerular filtration rate (GFR). Data are median (range).

\begin{tabular}{lllc}
\hline & $\mathrm{D} 1$ & $\mathrm{D}_{2-5}(\mathrm{~A})$ & $\mathrm{D}_{2-5}(\mathrm{~B})$ \\
\hline $\begin{array}{l}\mathrm{GFR} \\
\left(\mathrm{ml}-\mathrm{min}^{-1} .\right.\end{array}$ & $125(103-152)$ & $116(93-145)$ & $74(24-89)$ \\
$\left.\left(1.73 \mathrm{~m}^{2}\right)^{-1}\right)$ & & & \\
$\begin{array}{l}\mathrm{UAE} \\
(\mu \mathrm{g} / \mathrm{min})\end{array}$ & $4(3-7)$ & $93(8-1792)$ & $1201(9-4636)$ \\
$\begin{array}{l}\mathrm{UIgGV} \\
(\mu \mathrm{g} / \mathrm{min})\end{array}$ & $2.5(1.8-11.2)$ & $9.9(2.4-77.4)$ & $57.5(2.4-241.8)$ \\
\hline
\end{tabular}

UIgGV, Urinary IgG excretion rate 


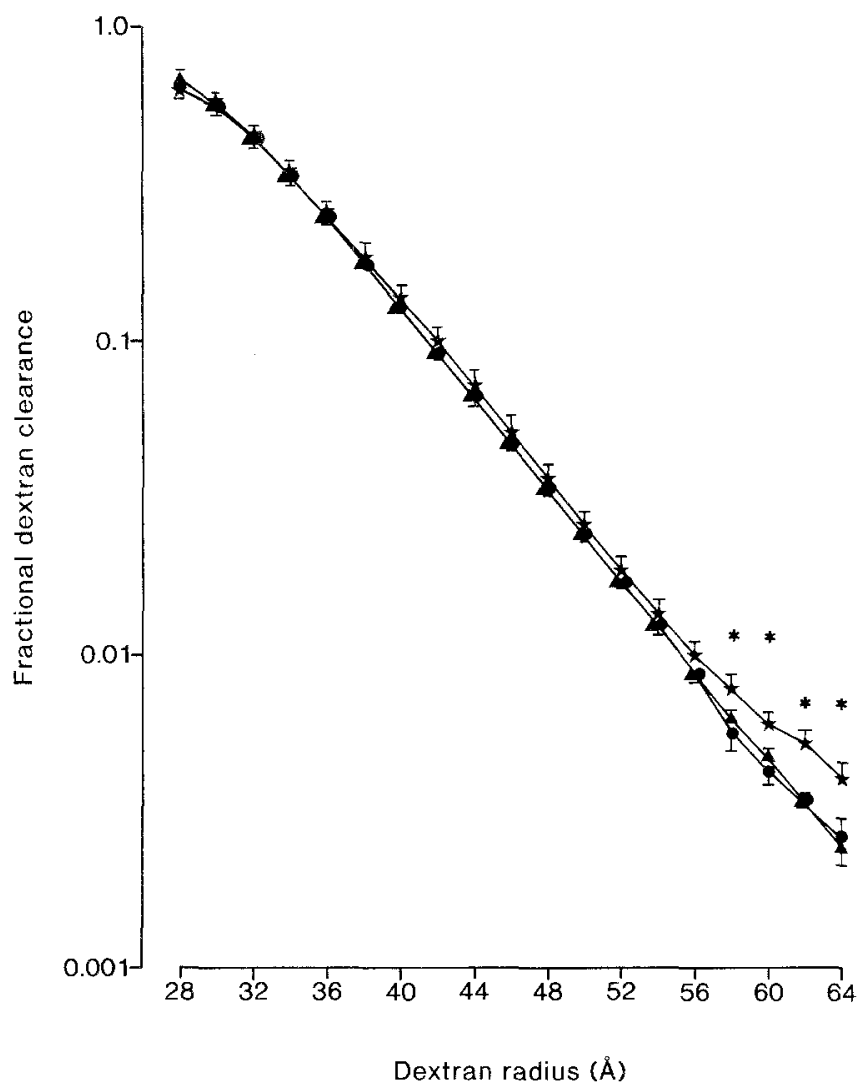

Fig.3. Fractional clearance (mean \pm SEM) of dextrans of different size $(\AA)$ in Type 1 diabetic patients with normal urinary albumin excretion (UAE) (<30 mg/24 h, glomerular filtration rate (GFR) greater than $\left.90 \mathrm{ml} \cdot \mathrm{min}^{-1} \cdot\left(1.73 \mathrm{~m}^{2}\right)^{-1}, \mathrm{D} 1, n=11, \bullet\right)$, patients with persistently elevated UAE ( $>30 \mathrm{mg} / 24 \mathrm{~h}$, GFR greater than $90 \mathrm{ml} \cdot \mathrm{min}^{-1} \cdot\left(1.73 \mathrm{~m}^{2}\right)^{-1}, n=21$, $\left.\mathbf{\Delta}\right)$ and patients with elevated UAE but GFR less than $\left.90 \mathrm{ml} \cdot \mathrm{min}^{-1} \cdot\left(1.73 \mathrm{~m}^{2}\right)^{-1}, n=19, \star\right)$. Further characteristics are given in Table $4 . * p<0.05$

\section{Discussion}

This is the first study to combine the measurements of dextran clearance and $\mathrm{IgG} / \mathrm{IgG} 4$ selectivity in a diabetic population including a full range of stages in the development of diabetic nephropathy, and diabetic patients with normal UAE.

Fractionated dextran clearance and $\mathrm{IgG} / \mathrm{IgG} 4$ selectivity represent the best available methods for determination of glomerular size- and charge selectivity in a clinical setting. Dextran is a well-established tracer, it is not reabsorbed in the tubules and narrow size fractioning enables studies of filtration barrier size selectivity. The IgG/IgG4 selectivity index (SI) is less established, but still the most used index of glomerular charge selectivity. The weaknesses of these methods should, however, not be ignored. Dextran polymers may, through their random coiling nature, be able to pass glomerular pores that restrict the passage of spherical proteins. Therefore dextran clearances may overestimate glomerular pore size, or falsely predict existence of non-selective glomerular pathways. The major disadvantage of the SI is that the proteins are reabsorbed in the tubules, $(90 \%$ under normal conditions [14]), causing the index to reflect the composite action of glomerular and tubular handling. Another source of error that might contribute to the scatter of the index is local (post-glomerular) production of IgG. Both methods share the drawback that pre-membrane solute concentrations, i. e. the concentration of dextran and IgG at the luminar capillary surface, must be assumed to equal the circulating plasma concentration. It is, however, unlikely that these weaknesses obscure the significance of the present findings.

Patients were subgrouped according to typical stages of diabetic nephropathy, and matched according to key clinical characteristics. In agreement with previous findings [15], there was no elevation of mean blood pressure in patients with slightly elevated UAE (D2).

Filtration fraction was not elevated in patients with early nephropathy. Previous studies have shown unchanged [16], elevated [17] or reduced [18] filtration fraction in these patients. Since filtration surface and oncotic pressure are unchanged in patients with UAE between $30-100 \mathrm{mg} / 24 \mathrm{~h}[19,20]$, we suggest that intraglomerular pressure is not elevated in these patients compared to normoalbuminuric diabetic patients.

In healthy control subjects the glomerular filtration process is charge selective [21]. The results of the present and previous studies $[4,5]$ are in agreement with this assumption since mean fractional clearance of $\operatorname{IgG}$ was about $50 \%$ higher in control subjects and patients with normal UAE compared to the clearance of IgG4. This results in an SI greater than 1.0. In diabetic patients with increased UAE, SI was reduced. Previous studies in advanced stages of diabetic nephropathy utilizing different endogenous protein markers have demonstrated loss of renal charge selectivity [4, 5, 22-24]. The present study, however, offers the first demonstration of reduced SI during the early stage of diabetic nephropathy. Patients with minimal albuminuria (group D2) had a significantly reduced SI and the SI remained reduced in all the groups with increased UAE. The demonstration of these dramatic alterations in patients with only slightly increased UAE we attribute to an improvement in the sensitivity of the ELISA assays and the urine storage conditions [9] having reduced the variation in the index by a factor 10 compared to the recent report of Pietravalle et al. [22].

The reason for the reduced SI in the albuminuric patients is not quite clear. In the tubules the reabsorption of negatively charged proteins is restricted favouring their excretion compared to neutral or positively charged proteins $[25,26]$. Thus glomeruli and tubules exert opposite effects on SI. Our findings of reduced SI in patients with increased UAE could be explained either by loss of glomerular charge selectivity with unaltered tubular function or by an increase of anionic tubular charges with unaltered glomerular charge selectivity. Up to now evidence of an increased anionic tubular charge in patients with insulin-dependent diabetes is lacking whereas the recent observation of a negative correlation between glomerular basement membrane anionic sites and albuminuria in diabetic patients indicates glomerular alterations in patients with albuminuria [27]. We, therefore, suggest that the difference of SI between patients with and without albuminuria is due to loss of glomerular charge selectivity. 
The demonstration of a normal urinary excretion of $\beta 2$ microglobulin - a marker of tubular reabsorption of proteins - in patients with normal GFR by our group and others $[2,4]$ is in agreement with this assumption. The fact that albuminuric patients have a mean SI below 1 as also found by Nakamura and Myers [5] can easily be understood if one assumes loss of glomerular but persisting tubular charge selectivity in these patients i. e. lower tubular reabsorption of anionic plasma proteins.

Fractional dextran clearances in healthy control subjects were very similar to those reported by Myers and coworkers $[18,28]$. Within the range 30 to $55 \AA$ values overlap $\pm 10 \%$, illustrating the precision in the measurements and the comparability with previous studies. Increased clearance of the largest dextrans was found only in the most advanced stage of diabetic nephropathy. Regrouping albuminuric patients revealed a more significant elevation of large dextran clearances in patients with reduced GFR. Correlations of both GFR and fractional IgG clearance with fractional clearances of 58-62 A dextrans were dependent on patients with reduced GFR.

Myers and co-workers [29] previously found a decrease in the slope of the dextran clearance curve in patients with advanced nephropathy. In "mild" nephropathy (comparable to our group D5), decreased slope of the clearance curve was found in one study [29], and reduction in clearance of small dextrans in another [5]. Our study confirms the elevated clearance of large dextrans in advanced nephropathy, but not a change in the slope of the dextran clearance curve. A general reduction of dextran clearances in the diabetic groups D1-D4 compared to healthy control subjects, similar to the finding by Nakamura and Myers [5], may not be related to diabetic nephropathy but rather to diabetes per se, since we also find it in normoalbuminuric (D1) patients. Thus abnormal glomerular size selectivity can be demonstrated only in the advanced stages of diabetic nephropathy.

It is not possible to calculate a true glomerular pore size from the dextran clearance data. Functionally however, the parallel dextran clearance curves indicate that the effective size selectivity of the major part of the filtration barrier remains unchanged during the progression of albuminuria. Interestingly, a calculation of this "effective pore size" (based on differentiation of the dextran clearance curves, data not shown) discloses a minor $(1 \AA)$ reduction in group D5, in perfect agreement with previous findings [30].

The theoretical "isoporous plus shunt" model suggests that development of proteinuria in diabetic nephropathy is associated with a shunt allowing unrestricted passage of plasma proteins at a rate up to $6 \%$ of the GFR [28]. Difficulties in applying models to experimental data are however illustrated by a recent study where neither the "isoporous plus shunt" nor a lognormal pore model fitted the experimental data [31]. Moreover, abnormalities in calculated membrane parameters have always been associated with differences in the fractional dextran clearance curves. We therefore prefer to compare the experimental data directly, rather than model-based membrane parameters. Our data do not contradict the "isoporous plus shunt" model. It can be calculated that any shunt-induced increment in the fractional clearance of a $60 \AA$ dextran (assuming $0 \%$ shunt in normoalbuminuric control subjects) in patients with minor elevation of $\operatorname{IgG}$ clearance (groups D2, D3) will be less than $10 \%$, far below the detection limit of the present studies. Therefore, whereas the initial increase in UAE can be explained by loss of glomerular charge selectivity, increase in excretion of IgG may still be explained by the formation of a new macromolecular pathway. It that case, the significant elevation of total IgG clearance in our group D3 and possibly also in some of the patients from D2 suggests the appearance of such new pathways in close association to the development of microalbuminuria.

We conclude that loss of glomerular charge selectivity either precedes or accompanies the formation of new glomerular macromolecular pathways in the development of diabetic nephropathy. Neither glomerular haemodynamic changes nor changes in the size restrictive filtration properties of the major glomerular filtration barrier were found at the early stages of diabetic nephropathy.

Acknowledgements. We are grateful for the expert technical assistance of Ms M. Deckert, Ms U.Søegaard, Ms K. Jensen, Ms L. Wlazlo and Ms L. Rosendal Nielsen.

\section{References}

1. Mathiesen ER, Rønn B, Jensen T, Storm B, Deckert T (1990) Relationship between blood pressure and urinary albumin excretion in development of microalbuminuria. Diabetes 39: 245-249

2. Feldt-Rasmussen B (1989) Microalbuminuria and clinical nephropathy in type 1 (insulin-dependent) diabetes mellitus: pathophysiological mechanisms and intervention studies. Dan Med Bull 36: 405-415

3. Zatz R, Meyer TW, Rennke HG, Brenner BM (1985) Predominance of hemodynamic rather than metabolic factors in the pathogenesis of diabetic nephropathy. Proc Natl Acad Sci USA 82: 5963-5967

4. Deckert T, Feldt-Rasmussen B, Djurup R, Deckert M (1988) Glomerular size and charge selectivity in insulin-dependent diabetes mellitus. Kidney Int 33: 100-106

5. Nakamura Y, Myers BD (1988) Charge selectivity of proteinuria in diabetic glomerulopathy. Diabetes 37: 1202-1211

6. Dalton RN, Wiseman MJ, Turner C, Viberti GC (1988) Measurement of urinary para-aminohippuric acid in glycosuric diabetics. Kidney Int 34: 117-120

7. Ljungström $\mathrm{KG}$, Renck $\mathrm{H}$, Hedin $\mathrm{H}$, Richter W, Wiholm BE (1988) Hapten inhibition and dextran anaphylaxis. Anaesthesia 43: 729-732

8. Feldt-Rasmussen B, Dinesen B, Deckert M (1985) Enzyme immuno assay - an improved determination of urinary albumin in diabetics with incipient nephropathy. Scand J Clin Lab Invest 45 : $539-544$

9. Kofoed-Enevoldsen A, Jensen K, Beck TC (1991) Measuring urinary IgG and IgG-4 excretion. Clin Chem 37: 1136 (Letter)

10. Fomsgaard A, Feldt-Rasmussen B, Deckert M, Dinesen B (1987) Micro-ELISA for the quantitation of human urinary IgG. Scand J Clin Lab Invest 47: 195-198

11. Feldt-Rasmussen B, Deckert M, Dinesen B (1986) Beta ${ }_{2}$-microglobulin in urine and serum determined by a micro-ELISA technique. Scand J Clin Lab Invest 46: 791-793

12. Gregg EC (1951) Absolute measurement of vibratory threshold. Arch Neurol Psych 66: 403-411 
13. Ewing DJ, Clark BF (1982) Diagnosis and management of diabetic autonomic neuropathy. Br Med J 285: 916-918

14. Mogensen CE, Sølling K. (1977) Studies on renal tubular protein reabsorption: partial and near complete inhibition by certain amino acids. Scand J Clin Lab Invest 37: 477-486

15. Mathiesen ER, Oxenb $\varnothing 11$ B, Johansen K, Svendsen PA, Deckert $T$ (1984) Incipient nephropathy in type 1 (insulin-dependent) diabetes. Diabetologia 26: 406-410

16. Feldt-Rasmussen B, Baker L, Deckert T (1985) Exercise as a provocative test in early renal disease in type 1 (insulin-dependent) diabetes: albuminuric, systemic and renal haemodynamic responses. Diabetologia 28: 389-396

17. Christensen CK (1991) The pre-proteinuric phase of diabetic nephropathy. Dan Med Bull 38: 145-159

18. Scandling JD, Myers BD (1992) Glomerular size-selectivity and microalbuminuria in early diabetic glomerular disease. Kidney Int 41: 840-846

19. Ellis EN, Steffes MW, Goetz FC, Sutherland DER, Mauer SM (1986) Glomerular filtration surface in Type 1 diabetes mellitus. Kidney Int 29: 889-894

20. Hommel E, Mathiesen ER, Aukland K, Parving H-H (1990) Pathophysiological aspects of edema formation in diabetic nephropathy. Kidney Int 38: 1187-1192

21. Rennke HFG, Cotran RS, Venkatachalam MA (1975) Role of molecular charge in glomerular permeability: tracer studies with cationized ferritins. J Cell Biol 67: 638

22. Pietravalle P, Morano S, Christina G et al. (1991) Charge selectivity of proteinuria in type 1 diabetes explored by immunoglobulin subclass clearance. Diabetes 40: 1685-1690

23. Kverneland A, Feldt-Rasmussen B, Vidal P et al. (1986) Evidence of changes in renal charge selectivity in patients with type 1 (insulin-dependent) diabetes mellitus. Diabetologia 29: 634-639

24. Fox JG, Quin JD, Paterson KR, O'Reilly DS, Boulton-Jones JM (1990) Impaired glomerular charge selectivity in microalbu- minuria and diabetic nephropathy. Diabetologia 33 [Suppl]: A67 (Abstract)

25. Christensen EI, Rennke HG, Carone FA (1983) Renal tubular uptake of protein: effect of molecular charge. Am J Physiol 244: F436-F441

26. Christensen EI, Carone FA, Rennke HG (1981) Effect of molecular charge on endocytic uptake of ferritin in renal proximal tubule cells. Lab Invest 44: 351-358

27. Vernier RL, Steffes MW, Sisson-Ross S, Mauer SM (1992) Heparan sulfate proteoglycan in the glomerular basement membrane in type 1 diabetes mellitus. Kidney Int 41: 1070-1080

28. Deen WM, Bridges CR, Brenner BM, Myers BD (1985) Heteroporous model of glomerular size selectivity, application to normal and nephrotic humans. Am J Physiol 249: F374-F389

29. Friedman S, Jones HW, Golbetz HV, Lee JA, Little HL, Myers BD (1983) Mechanisms of proteinuria in diabetic nephropathy. II. A study of the size-selective glomerular filtration barrier. Diabetes 32: $40-46$

30. Tomlanovich S, Deen WM, Jones HW III, Schwartz HC, Myers BD (1987) Functional nature of glomerular injury in progressive diabetic glomerulopathy. Diabetes 36: 556-565

31. Myers BD, Nelson RG, Williams GW et al. (1991) Glomerular function in Pima Indians with noninsulin-dependent diabetes mellitus of recent onset. J Clin Invest 88: 524-530

Received: 4 May 1992

and in final revised form: 2 November 1992

Dr. T. Deckert

Steno Diabetes Center

2, Niels Steensens Vej

DK-2820 Gentofte

Denmark 